\title{
JUVENILE AGGRESSIVE FIBROMATOSIS OF MAXILLA: A CASE REPORT
}

Biplab Nath ${ }^{1}$, Abhijit Datta르, Binay Debbarma33, Subrata Biswas ${ }^{4}$

\section{HOW TO CITE THIS ARTICLE:}

Biplab Nath, Abhijit Datta, Binay Debbarma, Subrata Biswas. "Juvenile Aggressive Fibromatosis of Maxilla: A Case Report". Journal of Evolution of Medical and Dental Sciences 2014; Vol. 3, Issue 20, May 19;

Page: 5399-5403, DOI: $10.14260 /$ jemds/2014/2604

ABSTRACT: Aggressive fibromatosis is best defined as a group of non-encapsulated, nonmetastasizing fibrous tumors that have tendency for local recurrence. This benign tumor is histologically characterized by fibroblastic proliferation and clinically by the potential to infiltrate and to recur after surgical excision, but does not metastasize. Its occurrence in the head and neck region is not common and very sporadically it may occur in the oral cavity or jaw bones. Its occurrence in the maxilla is even more exceptional .The clinical, radiographic and histological findings of a rare case of aggressive fibromatosis of the maxilla in a six-year-old female patient are presented here. The patients underwent surgical resection with wide surgical margins; excised material was analyzed microscopically and a diagnosis of fibromatosis was rendered.

KEYWORDS: Fibromatosis. Aggressive, Juvenile.

KEYMESSAGES: Aggressive Fibromatosis a rare tumor of Head \& Neck region which posses with a diagnostic dilemma at times due to its close histological similarity with fibro sarcoma. High index of suspicion is necessary for early diagnosis of such case.

INTRODUCTION: Aggressive fibromatosis is a non-metastasizing tumor-like fibroblastic growth of unknown pathogenesis involving voluntary muscle as well as aponeurotic and facial structures. The lesion has a strong tendency for local recurrence and aggressive infiltrating growth. It is most common in the shoulder girdle, the thigh and gluteal region of growing adults. ${ }^{1}$

Occurrence of fibromatosis in the head and neck region is not common (5-10\%) and only sporadically does it occur in the oral cavity or maxillary bones. Head-and-neck aggressive fibromatosis usually occurs in children under 20 years of age. ${ }^{2}$ It is more prevalent in adult females.

Clinically, in the oral cavity it usually presents as a painless mass or swelling in the region involved. It may attain a large size and cause compression, infiltration, and destruction of adjacent structures. Such growth behavior presents severe management problems, especially in the head and neck region, making complete excision of the tumor difficult.

The treatment of aggressive fibromatosis is traditionally surgical resection with an area of tumor free tissue. But when the complete surgical excision is not possible, radiation and chemotherapy also can be used.

Macroscopically, fibromatosis traditionally appears as an ill-defined and firm greyish-white mass. Histologically, it is composed of well-differentiated fibroblasts, fibrocytes and myofibroblasts within a collagenous to myxoid stroma. No atypical mitosis or anaplastic elements are seen.

Here, we report such a rare case of fibromatosis of the maxilla. The patient was treated with wide surgical resection with adequate surgical margins; excised material was analyzed microscopically and a diagnosis of aggressive fibromatosis was confirmed. 
Case History: A 6 years old female patient of a remote tribal hamlet of Tripura reported to Department of Otorhinolaryngology with huge swelling of right cheek. The swelling was painless and progressive in nature. With-in six months it assumed the size of big Pomelo [Fig-1]. Besides huge disfigurement of right face child also complained of complete bilateral nasal obstruction, lacrimation from same side with double vision and difficulty in eating foods. There was no past history of trauma. On examination swelling was about $20 \mathrm{~cm}$ in longest diameter and bony hard in consistency. Skin overlying the swelling was free but overstressed. Expansion of hard palate was noticed with irregular dentition of upper jaw.

Hard palate was yielding in nature and bulging in to the oral cavity. Due to extensive expansion of the tumor into maxillary sinus and ipsilateral nasal cavity the child lost her nasal patency completely. Expansion into lateral wall of maxilla and zygomatic bone resulted with disfigurement of right eye. However, no lymph node insolvent was observed.

Radiological Finding: Occipitomental view of X-ray PNS showed homogenous opacity of almost whole of right side of face. $\mathrm{C}$ T scan revealed huge expansile lesion measuring approximately $20 \mathrm{~cm}$ in diameter with foci of mineralization involving the right maxilla with destruction of alveolar arch of right maxilla and anterolateral wall with compression of Nasal cavity, nasopharynx, adjacent Para nasal sinuses and right orbital cavity [Fig-2].

Results of aspiration cytology on two occasions were inconclusive. Therefore, excision biopsy was planned.

Treatment - Excision: Tumour was excised under general anesthesia with adequate safety margins with prior elective tracheotomy [Fig-3]. Large surgical defect was repaired with remodelling of residual bony parts and overlying skin. Post-operative period was uneventful except some flap necrosis at nasolabial area which was corrected with second stage forehead rotational flap. All tissue obtained during primary surgery were submitted for histopathological study Microscopic examination revealed a feature of connective tissue proliferation, predominantly of fibroblastic cells in a background of moderate amount of collagen tissue. The cells were large, oval and fibroblastic in nature but pleomorphism was abundant. The blood vessels seemed to be constricted due to the high proliferative nature of the cells around [Fig-4]. Thus, final diagnosis of aggressive fibromatosis was made. The patient was put on regular follow up; no sign of recurrence noted so far [Fig- 5].

DISCUSSION: Aggressive fibromatosis is a histologically benign yet clinically invasive lesion that involves the jaws. ${ }^{3}$ The hallmark of this neoplasm is its high incidence of recurrence (up to 63\%). ${ }^{4}$ Patients with aggressive fibromatosis often present with a deep, firm mass with or without pain. ${ }^{5}$ Mandible is more frequently involved than the maxilla. Females are more commonly affected than males. ${ }^{6}$

The histopathologic differentiation between aggressive fibromatosis and other closely related spindle cell lesions like fibrosarcoma, neurofibroma, nodular fascitis, fibrous histiocytoma and infantile myofibromatosis is a challenge to the pathologist as it requires expertise to differentiate the finer details. Fibromatosis has a more uniform growth pattern, more mature cells and a paucity of mitosis compared with fibrosarcoma. ${ }^{7}$ Findings of pre-operative aspiration cytology of the tumour on two occasions were different, hence non conclusive. 
The final diagnosis of aggressive fibromatosis was based on a number of factors which included spindle shaped monotonous population of fibroblasts arranged in a whorl like and fasiculated pattern and the presence of collagen. ${ }^{8}$

The treatment of aggressive fibromatosis is traditionally surgical resection with an area of tumor free tissue. ${ }^{6}$ Radiation therapy has been used alone when resection might lead to serious morbidity and loss of function and when tumor is inoperable or there is gross residual disease after operative debulking. ${ }^{5}$ Chemotherapy alone does not appear to be curative, but it may be effective in controlling unresectable tumors, or in reducing tumor size before surgery. Chemotherapy in combination with enblock resection has also been effective in managing recurrent disease. ${ }^{7}$

The treatment of aggressive fibromatosis is traditionally surgical resection with an area of tumor free tissue. But when the complete surgical excision is not possible, radiation and chemotherapy also can be used. ${ }^{9}$

The prognosis depends entirely upon the initial treatment; if this is inadequate, the tumor will recur one or more times and progress. ${ }^{10}$ In this particular case tumour was adequately excised and no sign of recurrence is noted at one year follow- up.

CONCLUSION: Aggressive Fibromatosis a rare tumour of Head \& Neck region which posses with a diagnostic dilemma at times due to its close histological similarity with fibro sarcoma. Accurate diagnosis is imperative for consideration of appropriate management. Such a rare case is reported here with an unusual presentation.

\section{REFERENCES:}

1. Shafer WG, Hine MK, Levy BM. A textbook of Oral pathology $4^{\text {th }}$ edition. Churchill Livingston: $171,1984$.

2. Coffin CM: Fibromyoblastic-myofibroblastic tumors. In: Coffin CM, Dehner LP, O'Shea PA, ed. Pediatric soft tissue tumors: A clinical, pathological, and therapeutic approach, Philadelphia: Williams \& Wilkins; 1997:133-178.

3. Rodu B, Weathers DR, Campbell WG, Jr. Aggressive fibromatosis involving the paramandibular soft tissues. A study with the aid of electron microscopy. Oral Surg Oral Med Oral Pathol, 1981 Oct; 52(4):395-403.

4. Darlow L. Aggressive Fibromatosis of the Jaws: Combined Surgical-Chemotherapeutic Approach. Journal of Oral and Maxillofacial Surgery 1991; 49(8):116-7.

5. Hu T, Jing G, Lv K. Aggressive fibromatosis in the maxilla. British Journal of Oral \& Maxillofacial Surgery 2009; 47(2):129-31.

6. Donohue W, Malexos D, Pham H. Aggressive fibromatosis of the maxilla: report of a case and review of the literature. Oral Surg Oral Med Oral Pathol 1990; 69(4):420-6.

7. Fowler CB, Hartman KS, Brannon RB. Fibromatosis of the oral and paraoral region. Oral Surg Oral Med Oral Pathol 1994; 77: 373 -86.

8. Shetty Devi C, Aadithya B, Sikka Seema. Aggressive Fibromatosis versus low grade Fibrosarcoma -a diagnostic dilemma. International Journal of Pathology; 2010; 8(1): 30-33.

9. Choi JS, Lee GH, Kim HS, Sung DK, Kim KJ, Jeong JC, Ha SY, Cho H. Aggressive Fibromatosis of the maxilla. J Korean Assoc Oral Maxillofac surgery 1998; 24(2):241-245. 


\section{CASE REPORT}

10. Wilkins Jr S, Waldron C, Mathews W, Droulias C. Aggressive fibromatosis of the head and neck. American Journal of Surgery, 1975; 130(4): 412.

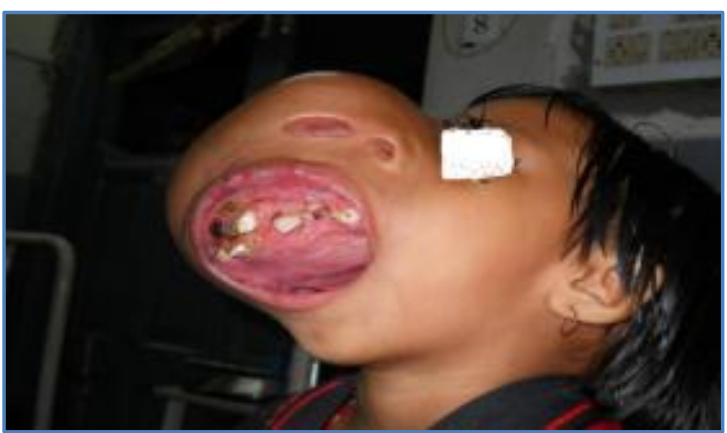

Fig. 1: Clinical Picture of the patient

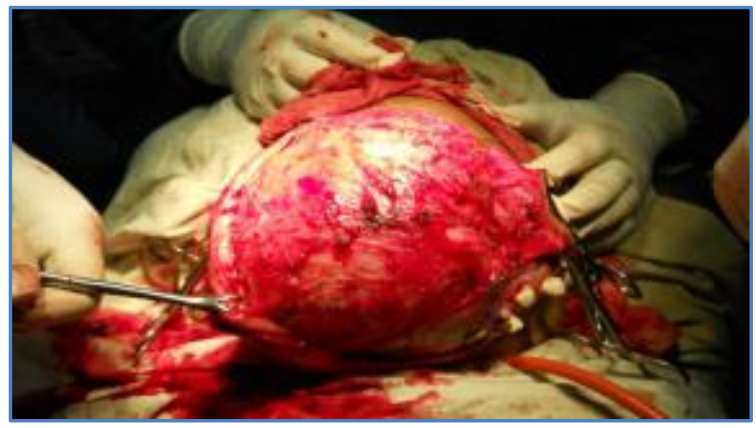

Fig. 3: Intra operative photograph

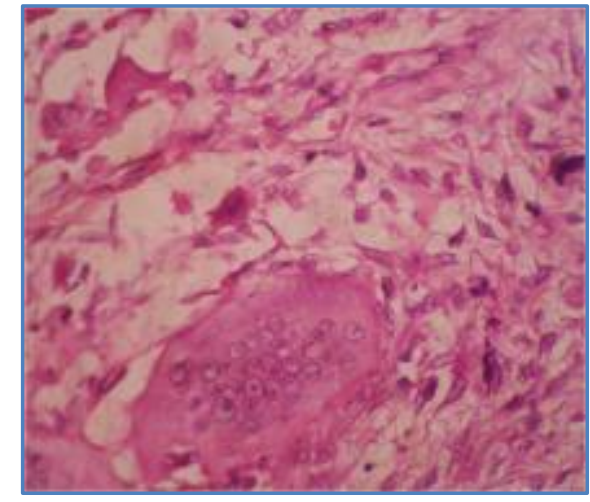

Fig. 5: Photomicrograph of the histopathologic section of the lesion (H \& E, 200X)

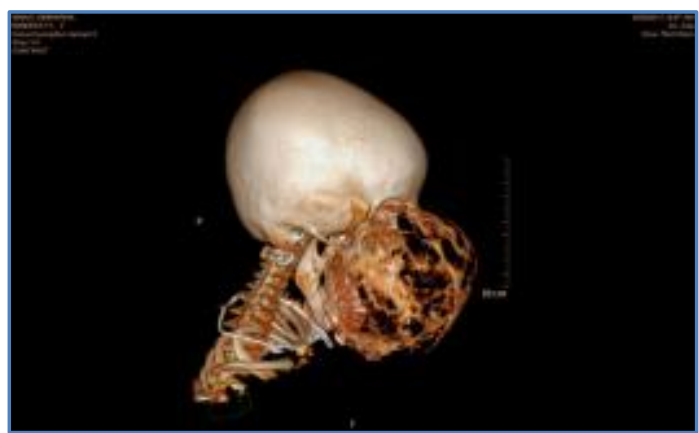

Fig. 2: 3D reconstruction of CT scan of the patient

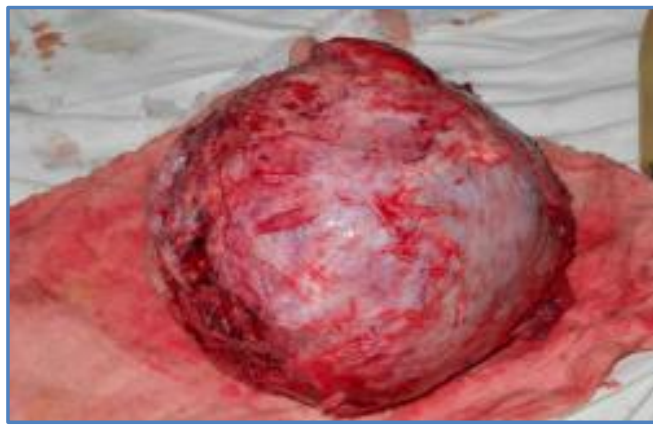

Fig.4: Tumour after excision

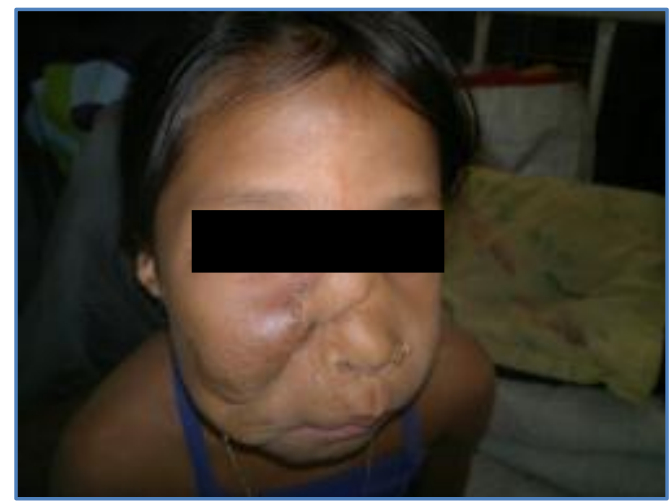

Fig. 6: Follow up after one year 


\section{CASE REPORT}

\section{AUTHORS:}

1. Biplab Nath

2. Abhijit Datta

3. Binay Debbarma

4. Subrata Biswas

\section{PARTICULARS OF CONTRIBUTORS:}

1. Associate Professor, Department of ENT, Agartala Government Medical College.

2. Associate Professor, Department of Pathology, Agartala Government Medical College.

3. Registrar, Department of ENT, Agartala Government Medical College.
4. Post Graduate Trainee, Department of ENT, Agartala Government Medical College.

\section{NAME ADDRESS EMAIL ID OF THE CORRESPONDING AUTHOR:}

Dr. Biplab Nath,

Malancha Nagar Road,

P. O. Kunjaban,

Agartala, Tripura-799006.

Email: biplabgdr@gmail.com

Date of Submission: 29/04/2014.

Date of Peer Review: 30/04/2014.

Date of Acceptance: 08/05/2014.

Date of Publishing: 13/05/2014. 